\title{
REE and Nd isotopes in sedimentary Fe oxides as proxies for shale weathering
}

GERMAIN BAYON ${ }^{1}$, KWANGCHUL JANG ${ }^{2}$, NATHALIE VIGIER $^{3}$, KAZUYO TACHIKAWA ${ }^{4}$, CHRISTINA LARKIN ${ }^{5}$, ALEXANDER PIOTROWSKI $^{5}$ AND EDWARD TIPPER ${ }^{6}$

${ }^{1}$ IFREMER

${ }^{2} \mathrm{KOPRI}$

${ }^{3}$ LOV - CNRS - Sorbonne Université

${ }^{4}$ Aix Marseille Univ, CNRS, IRD, INRAE, Coll France, CEREGE

${ }^{5}$ University of Cambridge

${ }^{6}$ Cambridge

Presenting Author: germain.bayon@ifremer.fr

Chemical weathering plays an important role in sequestering atmospheric $\mathrm{CO}_{2}$, but its potential influence on global climate over geological timescales remains debated. To some extent, this uncertainty arises from the difficulty in separating the respective contribution of sedimentary and crystalline silicate rocks to past weathering rates in the geological record; two types of rocks having presumably different impact on the long-term carbon cycle. Here, we present a novel method for tracing the origin of weathered rocks on continents, based on the measurement of $\mathrm{REE}$ and $\mathrm{Nd}$ isotopes $\left(\mathrm{e}_{\mathrm{Nd}}\right)$ in leached iron oxide fractions of river sediments $[1,2]$. We show that the degree of mid-REE enrichment in leached sediment phases provides information on the source of $\mathrm{Fe}$ oxides, indicating the presence of ancient marine $\mathrm{Fe}$ oxides derived from the erosion of sedimentary rocks or more recent secondary oxides formed in soils via silicate weathering. We also demonstrate that the $\mathrm{e}_{\mathrm{Nd}}$ difference between paired $\mathrm{Fe}$ oxide and detrital fractions in river sediments $\left(\mathrm{De}_{\mathrm{Nd}}\right.$ Feox-Det) reflects the relative contribution of sedimentary vs crystalline silicate rocks during weathering. Rivers draining old cratons and volcanic provinces display near-zero $\mathrm{De}_{\mathrm{Nd}}$ Feox-Det values indicative of dominant silicate weathering $(0.5 \pm 1.1)$, while multi-lithological catchments hosting sedimentary formations yield systematically higher values $(2.7 \pm 1.2)$. Taken together, these findings show that sedimentary rock weathering can be traced by the occurrence of riverine $\mathrm{Fe}$ oxides having more radiogenic $\mathrm{Nd}$ isotope signatures compared to detrital fractions. Finally, the influence of climate and geomorphic parameters on the $\mathrm{Nd}$ isotopic composition of sedimentary Fe oxides will be discussed, together with future perspectives.

[1] Bayon et al. (2020) Chem. Geol. 553, 119794

[2] Jang et al. (2020) EPSL 542, 116319 